\title{
Misrepresentation of hydro-erosional processes in rainfall simulations using disturbed soil samples
}

Edivaldo L. Thomaz ${ }^{1 *}$ and Adalberto A. Pereira

\begin{abstract}
Interrill erosion is a primary soil erosion process which consists of soil detachment by raindrop impact and particle transport by shallow flow. Interill erosion affects other soil erosion sub-processes, e.g., water infiltration, sealing, crusting, and rill initiation. Interrill erosion has been widely studied in laboratories, and the use of a sieved soil, i.e., disturbed soil, has become a standard method in laboratory experiments. The aims of our study are to evaluate the hydro-erosional response of undisturbed and disturbed soils in a laboratory experiment, and to quantify the extent to which hydraulic variables change during a rainstorm. We used a splash pan of $0.3 \mathrm{~m}$ width, $0.45 \mathrm{~m}$ length, and 0.1 $\mathrm{m}$ depth. A rainfall simulation of $58 \mathrm{~mm} \mathrm{~h}^{-1}$ lasting for $30 \mathrm{~min}$ was conducted on seven replicates of undisturbed and disturbed soils. During the experiment, several hydrophysical parameters were measured, including splashed sediment, mean particle size, runoff, water infiltration, and soil moisture. We conclude that use of disturbed soil samples results in overestimation of interrill processes. Of the nine assessed parameters, four displayed greater responses in the undisturbed soil: infiltration, topsoil shear strength, mean particle size of eroded particles, and soil moisture. In the disturbed soil, five assessed parameters displayed greater responses: wash sediment, final runoff
\end{abstract}


coefficient, runoff, splash, and sediment yield. Therefore, contextual soil properties are most suitable for understanding soil erosion, as well as for defining soil erodibility.

Keywords: Soil erodibility; Interrill methodology; Hydropedology; Root

\section{Introduction}

Soil, as a major component of the ecosystem, has been facing major challenges. Soil is essential for food production and environmental services, but climate change and population growth impose great pressure on soil, increasing its degradation including soil erosion (Montgomery, 2007; Editorial, 2010; Norvig et al., 2010). Soil erosion is one of the most important modes of land degradation worldwide. Important advances in the study of soil erosion have occurred in terms of the methodology, knowledge of processes, and modeling (Ellison, 1950; Emmett, 1970; Govers, 1992; Morgan, 2005; Boix-Fayos et al., 2006; Govers et al., 2007; Knapen et al., 2007; Grismer, 2012; Zhang et al., 2014). In spite of this progress, many research gaps still exist, such as lack of a reliable soil erodibility concept and information on the temporal variation of the soil erodibility coefficient. New methodologies to explore different soil erosion subprocesses and soil erosion data from diverse locations must be provided (Wang et al., 2013), including those for agricultural disturbed soil. However, there is a deficiency in soil erosion studies, particularly in relation to hydrology and geomorphological processes (Bryan, 2000).

Interrill erosion, the detachment of soil particles by raindrop impact and their transport by shallow surface flow, has been widely studied via laboratory experiments (Moldenhauer and Long, 1964; Bryan, 1979; Bradford et al., 1987; Bradford and Foster, 
51 1996; Fox and Bryan, 2000; Zhang et al., 2014). Laboratory experimentation has

52 become standard method for research on hillslope processes in geomorphology, despite its limitations; for example, the materials used and processes observed in laboratory experiments may be different from those measured in the field (Bennett et al., 2015).

The use of a sieved soil, i.e., disturbed soil in interrill research is almost standard in laboratory experiments (Mutchler et al., 1994; Agassi and Bradford, 1999). This methodology to study interrill soil erosion has received criticism, since the natural soil architecture is essential to understanding the numerous biogeophysical processes, including rainfall-runoff processes. Therefore, to understand soil hydro-physical processes, experiments on an intact undisturbed soil should be preferred (Lin et al., 2006). However, few studies have been conducted using undisturbed soil samples. Research on the mechanism of soil detachment by overland flow comparing disturbed and undisturbed soils indicate that soil detachment rates are 1 to 23 times greater for disturbed soils than for natural undisturbed soils (Zhang et al., 2003). They used small soil core samples with $10 \mathrm{~cm}$ diameter. Whereas Shi et al. (2010) evaluated the aggregate breakdown mechanisms in interrill erosion processes, and found a close relationship between the mechanism and erosion rates in both disturbed and undisturbed samples. However, the undisturbed soil was measured in the field, and the disturbed soil was measured in a laboratory.

Therefore, it is necessary to conduct more studies using undisturbed soil samples in order to understand the interrill process and to evaluate the influence of hydraulic parameters on detachment rates. In addition, it is necessary to quantify how the many hydraulic variables involved in interrill processes change during a rainstorm over undisturbed and disturbed soils. 
The aims of this study are to evaluate the hydro-erosional response of undisturbed and disturbed soils in laboratory experiments, to quantify the extent to which hydraulic variables change during a rainstorm and to discuss the contextual soil erodibility controlling factors. Establishing a model for soil erodibility and interrill erosion was not a primary objective of our study this time.

\section{Material and methods}

\subsection{Soil characteristics and collection of undisturbed and disturbed samples}

This study was developed for clay-textured Brown Oxisols according to the USDA soil taxonomy (USDA, 1998). The data on granulometry, chemical properties, organic carbon content, and grain size are shown in Table 1. The soil was collected in pair randomly (i.e., undisturbed plus disturbed sample) from an area ( 1 ha) forested with Pinus spp with slope of $\sim 6-12 \%$. The undisturbed sample was collected using an iron frame with the same dimensions as the splash pan, $30 \mathrm{~cm}$ wide, $45 \mathrm{~cm}$ long, and $10 \mathrm{~cm}$ deep. The iron frame with cutting edges was inserted into the soil, then the soil was extracted, and excess soil was removed from the sample. The soil sample bottom was cut with a steel wire. Then, in the field, the bulk soil was transferred carefully to a splash pan and prepared for rainfall simulation. The disturbed sample was collected from a site adjacent to the undisturbed sample site i.e., side by side. A shovel was used to excavate the soil to a depth of $10 \mathrm{~cm}$. The soil was transferred gradually to the splash pan, forming layers that were gently crushed and compacted. And the larger roots and clods over $20 \mathrm{~mm}$ was removed from the splash pan (Agassi and Bradford, 1999). 
The sample characteristics are summarized in Table 2. We attempted to reproduce the bulk density of the undisturbed soil in the disturbed samples (Table 2). The soil moisture content was measured before the rainfall simulation using a set of moisture sensors $(n=7)$, and was taken into account in the soil bulk density estimation. The soil bulk density was $5 \%$ greater in the undisturbed sample compared to the disturbed soil samples $(p>0.05)$. The rainfall simulation was performed on two consecutive days.

Table 2. Sample characteristics soil weight and estimated soil bulk density

Note: ${ }^{1}$ Undisturbed sample soil moisture $\left(0.161 \pm 0.034 \mathrm{~m}^{3} \mathrm{~m}^{-3}, n=7\right) ;{ }^{2}$ Disturbed sample soil moisture $\left(0.111 \pm 0.017 \mathrm{~m}^{3} \mathrm{~m}^{-3}, n=7\right)$.

\subsection{Experimental design}

The multi-drop simulator consisted of a framework of pipes (20 mm diameter) and a 6-m-tall SPRACO cone jet nozzle, and water was supplied by an electric water pump with a pressure of $78 \mathrm{kPa}$. The simulated rainfall was dripped from a height of $6 \mathrm{~m}$ from the central plot for a period of $30 \mathrm{~min}$ with a rainfall intensity of $58.2 \pm 7.3 \mathrm{~mm} \mathrm{~h}(n=$ 10). The drop diameter of the rainfall simulator varied from 0.35 to $6.35 \mathrm{~mm}$, with a median drop size of $2.4 \mathrm{~mm}$ and a coefficient of uniformity over $90 \%$. The device produced rain with $90 \%$ of the kinetic energy of natural rainfall, and with similar intensity (Luk et al., 1986). 
by a shield collector to measure the splash detachment (Bryan and De Ploey, 1983). In addition, the splash pan apparatus has a separate slot/trough to collect runoff and wash sediment, and a drainage outlet at the bottom to collect percolation (Fig. 1).

Fig. 1. Central splash pan test area surrounded by a shield collector to measure splash detachment.

During the simulation, the soil erosion pans were tilted to a $9 \%$ slope. Also, during the experiment, the water temperature $\left(18.2^{\circ} \mathrm{C} \pm 1.3^{\circ} \mathrm{C}\right)$ and water electric conductivity $(92.8 \pm 4.9 \mu \mathrm{S})$ were measured four times. Runoff was collected for $1 \mathrm{~min}$ at regular intervals of $2 \mathrm{~min}\left(\mathrm{~mm} \mathrm{~h}^{-1}\right.$ and \%), and time to runoff (min) was measured when continuous flow was recorded at the trough. The total runoff and sediment yield i.e., total sediment splashed plus sheet wash sediment $\left(\mathrm{kg} \mathrm{m}^{-2} \mathrm{~h}^{-1}\right)$ were calculated by integrating the 1-min runoff rates for the entire duration of the experiment. The entire percolation (i.e., infiltration - $\mathrm{mm} \mathrm{h}^{-1}$ ) was collected every 5 min. The total splash detachment $\left(\mathrm{kg} \mathrm{m}^{-2} \mathrm{~h}^{-1}\right)$ composed by the material retained in the splash pan shield was collected at the end of the simulation. The sheet wash $\left(\mathrm{kg} \mathrm{m}^{-2} \mathrm{~h}^{-1}\right)$ was collected for 1 min at regular intervals of 2 min. The material retained in the trough was put in a set of sieves with apertures of $2,1,0.5,0.250$, and $0.125 \mathrm{~mm}$ for dry sieving; in order to measure the mean particle size (mm) (Kemper and Rosenau, 1986).

5 Soil moisture $\left(\mathrm{m}^{3} \mathrm{~m}^{-3}\right)$ was measured throughout the rainfall simulation through one soil moisture sensor installed at $5 \mathrm{~cm}$ depth in each erosion pan, i.e., seven replicates. The device was set to record soil moisture every $1 \mathrm{~min}$. 

through a torsional vane shear; three replicates were collected in each soil erosion pan $(3 \times 7=21$ samples $)$.

Root mass (g) was measured after the rainfall simulation. Seven samples were collected randomly from the undisturbed and disturbed soils. The samples were collected with a ring of $257.6 \mathrm{~cm}^{3}$, and then the soil and root mass were washed in a sieve of $0.5 \mathrm{~mm}$ of opening (De Baets et al., 2006). Root length $(\mathrm{cm})$ was measured with a ruler, and root thickness was measured with a caliper.

\subsection{Statistical analyses}

Several parameters from the undisturbed and disturbed samples were compared in pairs. A comparison between seven replicate samples was performed by applying the standard t-test. The data were checked for homoscedasticity and heterocedasticity when performing the t-test. The statistical significance was represented by $*(p<0.05), * *(p$ $<0.01),{ }^{* * *}(p<0.001)$, and ns (not significant, $\left.p \geq 0.05\right)$.

Hierarchical cluster analysis, a numeric multivariate statistical technique, was applied to classify the samples by dividing the set of observations into homogenous groups according to some criteria. The Euclidean paired group method used in this technique computed distances, and the results were plotted in a dendrogram, which summarizes the information on the undisturbed and disturbed soil hydro-erosional processes (McGarigal et al. 2000). For the hydro-erosional parameters, groups were

170 formed through the use of seven parameters: total sediment splashed, sheet wash 171 sediment, sediment yield, runoff, infiltration, topsoil shear strength, and mean particle size. 


\section{Results}

175

176

177

\subsection{Soil hydro-erosional response}

The splash detachment was twice as large for the disturbed soil compared to the undisturbed sample (Fig. 2a). The splash for the undisturbed soil ranged from 0.261 to $0.525 \mathrm{~kg} \mathrm{~m}^{-2} \mathrm{~h}^{-1}$ (average $0.342 \pm 0.095 \mathrm{~kg} \mathrm{~m}^{-2} \mathrm{~h}^{-1}$ ), while the disturbed soil registered 0.537 to $1.193 \mathrm{~kg} \mathrm{~m}^{-2} \mathrm{~h}^{-1}$ (average $0.707 \pm 0.251 \mathrm{~kg} \mathrm{~m}^{-2} \mathrm{~h}^{-1}$ ).

The wash sediment from the disturbed soil was similar to that from the undisturbed soil (Fig. 2b). The wash sediment displayed greater variability (>70\%) between samples in both treatments. The wash sediment from the undisturbed soil ranged from 0.004 to $0.078 \mathrm{~kg} \mathrm{~m}^{-2} \mathrm{~h}^{-1}$ (average $0.049 \pm 0.029 \mathrm{~kg} \mathrm{~m}^{-2} \mathrm{~h}^{-1}$ ), and the disturbed soil registered 0.034 to $0.202 \mathrm{~kg} \mathrm{~m}^{-2} \mathrm{~h}^{-1}$ (average $0.081 \pm 0.056 \mathrm{~kg} \mathrm{~m}^{-2} \mathrm{~h}^{-1}$ ).

The sediment yield, i.e., splashed soil plus soil transported by wash and retained in the trough, was superior for the disturbed soil, at $0.788 \pm 0.256 \mathrm{~kg} \mathrm{~m}^{-2} \mathrm{~h}^{-1}$, compared to that of the undisturbed soil, at $0.391 \pm 0.111 \mathrm{~kg} \mathrm{~m}^{-2} \mathrm{~h}^{-1}$ (Fig. 2c). In both treatments, the splash detachment, collected in the splash pan shield, accounted for $88 \%$ and $90 \%$ of the total sediment detached from the undisturbed and disturbed soils, respectively.

Runoff registered from the disturbed soil was almost three times that of the undisturbed soil (Fig. 2d). The runoff from the undisturbed soil ranged from 2.9 to 9.5 $\mathrm{mm} \mathrm{h}^{-1}$ (average $5.7 \pm 2.2 \mathrm{~mm} \mathrm{~h}^{-1}$ ), while the disturbed soil registered runoff ranges from 8.2 to $21.9 \mathrm{~mm} \mathrm{~h}^{-1}$ (average $16.1 \pm 5.0 \mathrm{~mm} \mathrm{~h}^{-1}$ ).

Fig. 2. Comparison of the hydro-erosional and bio-physical parameters collected from undisturbed and disturbed soils.

Note: The error bars indicate one standard deviation 
199 Water infiltration in the undisturbed soil was $19.2 \mathrm{~mm} \mathrm{~h}^{-1}$, nearly five times greater than infiltration registered in the disturbed soil $\left(4.1 \mathrm{~mm} \mathrm{~h}^{-1}\right)$. In addition, the variability of water percolation was less in the undisturbed samples (17\%) compared to that in the

202 disturbed samples (66\%) (Fig. 2e).

The mean particle size of the aggregate detached by splash and transported by wash was greater for the undisturbed soil $(1.30 \pm 0.37 \mathrm{~mm})$ than for the disturbed soil samples $(0.93 \pm 0.18 \mathrm{~mm})$ (Fig. 2f). Moreover, the undisturbed soil exhibited only $3 \%$ of microaggregates $(<0.250 \mathrm{~mm})$, whereas the disturbed soil showed a greater quantity of microaggregates $(10 \%)$. Larger aggregates of $\geq 4.0 \mathrm{~mm}$ were practically absent from both soil-washed particles $(\sim 0.5 \%)$. The topsoil mean weight diameter registered in the field was $2.96 \pm 0.18 \mathrm{~mm}$, closer to the undisturbed soil sample than to the disturbed soil, despite the differences observed between the two samples.

In addition, the topsoil strength was greater in the undisturbed soil, at $1.69 \pm 0.40$ $\mathrm{kPa}$, than topsoil strength registered in the disturbed soil $(0.69 \pm 0.24 \mathrm{kPa})($ Fig. $2 \mathrm{~g})$. The topsoil strength registered in the field was $3.0 \pm 0.54 \mathrm{kPa}$, closer to values found in the undisturbed sample than in the disturbed sample. It is worth mentioning that the measurement of topsoil strength after the rainfall simulation was performed with high soil moisture content $\left(\sim 0.40 \mathrm{~m}^{3} \mathrm{~m}^{-3}\right)$, whereas, the topsoil strength measured in the field was collected with less soil moisture $\left(\sim 0.29 \mathrm{~m}^{3} \mathrm{~m}^{-3}\right)$.

The topsoil characteristics were different during the course of the experiment (Fig. 2h). Although based only on a visual qualitative assessment, the undisturbed soil had a rough surface, with some roots exposed by surface erosion (Fig. 3a). Meanwhile, the disturbed soil displayed large, stable aggregates isolated by rain splash and selective transport, particle scouring, and scattered points, with smooth surfaces with sealing and 
crusting (Fig. 3b). Another difference between undisturbed and disturbed soils was the presence of roots, and their characteristics (Fig. 3c, d). The primary roots had lengths ranging from 30 to $45 \mathrm{~cm}$, with a thickness of $0.44 \pm 0.05 \mathrm{~cm}$ (Fig. 3c), and were present only in the undisturbed soil. Secondary roots had a thickness of $0.10 \pm 0.04 \mathrm{~cm}$, and were present in both samples (Fig. 3d). However, roots with thicknesses of $0.1 \mathrm{~cm}$ were infrequently found in the disturbed soil, whereas roots with thicknesses $>0.1 \mathrm{~cm}$ and $<0.2 \mathrm{~cm}$ were abundant in the undisturbed soil (Fig. $3 \mathrm{~d}$ ). The secondary root mass was greater in the undisturbed soil, at $0.40 \mathrm{~g}$, in spite of its greater variability. The secondary root mass in the disturbed soil was $0.23 \mathrm{~g}$, and was more homogenous (Fig. $2 h)$.

Fig. 3. Overview of soil surface after rainfall simulation, and root characteristics: a) undisturbed soil; b) disturbed soil; c) primary roots; d) secondary roots

\subsection{Hydro-erosional performance of undisturbed and disturbed soil throughout experiment}

The accumulated sediment transported by sheet flow increased exponentially in the disturbed soil. At the end of the experiment, the accumulated sediment was nine times greater for the disturbed soil $\left(38.6 \mathrm{~g} \mathrm{~m}^{-2} \mathrm{~h}^{-1}\right)$ compared to the undisturbed soil $\left(4.3 \mathrm{~g} \mathrm{~m}^{-2}\right.$ $\mathrm{h}^{-1}$ ) (Fig. 4a). Runoff and sediment transport from the undisturbed soil started 3 min after the onset of rainfall, whereas for the disturbed soil, runoff and sediment transport occurred only after 9 to $12 \mathrm{~min}$ of rainfall. The accumulated runoff on the disturbed soil $\left(35 \mathrm{~mm} \mathrm{~h}^{-1}\right)$ was nearly four times greater than runoff registered on the undisturbed soil $\left(9.5 \mathrm{~mm} \mathrm{~h}^{-1}\right)$ (Fig. 4b). The runoff coefficient was measured in the last $3 \mathrm{~min}$ of the 
experiment, and the runoff coefficient of the undisturbed soil was much smaller (16\%) compared to the disturbed soil $(61 \%)$. However, the runoff coefficient based on the total runoff was much smaller for the undisturbed than for the disturbed soil, at $10 \pm 4 \%$ and $28 \pm 8 \%$, respectively.

Fig. 4. Comparison of hydro-erosional performance of undisturbed and disturbed soil: a) wash sediment, b) runoff, and c) soil moisture

Note: The error bars indicate one standard deviation

The soil moisture at the onset of the experiment was $0.161 \mathrm{~m}^{3} \mathrm{~m}^{-3}$ and $0.111 \mathrm{~m}^{3} \mathrm{~m}^{-3}$ for the undisturbed and disturbed soils, respectively (Fig. 4c). The soil moisture increased rapidly in the undisturbed soil, and after 10 min of rainfall simulation, the soil moisture reached $\sim 0.403 \mathrm{~m}^{3} \mathrm{~m}^{-3}$. In addition, the undisturbed soil displayed greater variability compared to the disturbed soil. Soil moisture in the disturbed soil increased progressively and took 16 min to reach $\sim 0.305 \mathrm{~m}^{3} \mathrm{~m}^{-3}$. Throughout the experiment, the disturbed soil moisture was lower than the undisturbed soil moisture. At the end of the measurement, i.e., after $30 \mathrm{~min}$, the soil moisture $\left(0.443 \mathrm{~m}^{3} \mathrm{~m}^{-3}\right)$ of the undisturbed soil was $31 \%$ higher than the soil moisture of the disturbed soil $\left(0.337 \mathrm{~m}^{3} \mathrm{~m}^{-3}\right)$.

Finally, Fig. 5 summarizes all the hydro-erosional parameters measured for the undisturbed and disturbed soils. We noticed a discrete variation in replicates of the same group, but not enough to separate these samples into dissimilar groups. However, there was a clear distinction and linkage between hydro-erosional performance of the undisturbed and disturbed soil samples. 
272 Fig. 5. Cluster analyses considering several hydro-erosional parameters measured for undisturbed (UND) and disturbed soils (DIS)

274

\section{Discussion}

276

We compared the hydro-erosional performance of the undisturbed and disturbed soil. Both soils exhibited completely different hydrological and erosional performance for several of the measured parameters. Of the nine assessed parameters, four displayed greater responses in the undisturbed soil: infiltration, topsoil shear strength, mean particle size of eroded sediment, and soil moisture. Meanwhile, the disturbed soil displayed greater responses for five assessed parameters: wash sediment, final runoff coefficient, runoff, splash, and sediment yield.

Table 3. Summary of hydro-erosional variable changes compared for undisturbed and disturbed soils topsoil in a no-tillage system (Bryan, 2000) or even that of forested soil (Douglas, 1999; Thomaz, 2013). Therefore, the high water infiltration, topsoil resistance, and aggregate stability prevent soil particle detachment. Furthermore, in this condition, there are fewer detached particles, the runoff erosivity is negligible, and the wash sediment transport is very low.

In contrast, the disturbed soil showed a hydro-erosional response similar to soil from a conventional tillage system or unstructured soil (Bryan, 2000; Lin et al., 2006). The rain splash detaches great quantities of soil particles. Fine particles clog the superficial 
porosity, increasing the runoff and wash particle transport, while infiltration is practically absent. This is significant because topsoil cohesiveness is of utmost importance to hydrological changes.

The key factor of our experiment results contrasting erosional processes in undisturbed and disturbed soil may be the way in which the soil surface responds to rainfall, as well how the surface changes during the course of rainfall (Fig. 3a, b). The erosional processes are dynamic, and the physical conditions of soil change greatly during a storm; the characteristics and extent of these changes are of great importance to the hydro-erosional performance of the soil (Bryan, 2000; Wang et al., 2013).

Aggregate stability affects several soil processes, especially water infiltration and, as a consequence, soil erosion. In disturbed soil, aggregate breakdown occurs because of compression during the wetting processes, as well as by raindrop impact. The aggregate disruptions leave the soil surface prone to sealing (Fig. 3b), resulting in decreased water infiltration and enhanced runoff (Bradford et al., 1987; Le Bissonnais, 1996).

Fig. 6 displays the contextual soil erodibility in order to summarize and explain the significance of our experiment procedures and results in terms of soil erodiblity. In short, soil erodibility is the capacity of soil to resist an erosional agent, or the susceptibility of soil to detachment and transport by erosion processes.

There is a long tradition of studying soil erodibility based on invariant soil properties such as clay ratio as a measure of susceptibility to soil erosion (Bouyoucos, 1935). In addition, indices for soil erodibility assessment have been proposed (Bryan, 1968); in particular, indices associated with the aggregate diameter and its behavior in response to erosional processes. These principles are based on intrinsic soil properties and their relationship with erosional processes (Fig. 6). 
An important advance in the study of soil aggregation was reached when organic

322

323

324

325

326

327

328

329

330

331

332

333

334

335

336

matter was recognized as an agent of aggregate stabilization. Moreover, different organic agents were classified as transient, tempory, and persistent, and each of them play a unique role in aggregate stability. The hierarchical levels of aggregate organization in microaggregates $(<0.250 \mathrm{~mm})$ and macroaggregates $(>0.250 \mathrm{~mm})$ follow the organic matter dynamics. Microaggregates are stabilized by transient and persistent organic carbon (polysaccharides), whereas macroaggregates are stabilized by tempory organic matter (roots and hyphae) (Tisdall and Oades, 1982). Soil structure is thus based on a close relationship between the building up processes (e.g., root and fungal hyphae growth, inorganic cementation, organic bonding and cohesion) and the opposite, breaking down processes (e.g., tillage, slaking, and dispersion) (Amézketa, 1999; Díaz-Zorita et al., 2002; Bronick and Lal, 2005).

Fig. 6. Diagram of contextual soil erodibility controlling factors

Soil tillage is the main factor affecting soil structure, aggregate stability, and soil erodibility. Soil in agricultural systems experience disturbance on the superficial soil horizon, compaction at different depths, decreased water infiltration and water retention capacity, suppression of subsuperficial flow, and enhancement of overland flow (Bryan, 2000; Hamza and Anderson, 2005; Bertolino et al., 2010; Thomaz, 2013). However, in agricultural areas, the crops increase the root density in the soil; as a result, the root networks increase the aggregate stability and soil resistance, and decrease the concentrated flow erosion rates (Gyssels and Poesen, 2003; De Baets et al., 2006; Baets et al., 2007; ). In addition, vegetation types affect soil resistance, aggregate stability, and 
shear strength in lands that have been converted from agricultural land to vegetated erosion protection areas (Fattet et al., 2011).

347 Finally, geo-ecosystem characteristics (e.g., climate), land use, and time have a major effect on the temporal variation of soil erodibility (Fig. 6). Soil erodibility is subject to large seasonal variation, with maximum values occurring during the winter, and minimum values in the summer. For this reason, soil samples for determining soil erodibility should be collected on different dates throughout the year, and a fixed index is fraught with difficulties (Imeson and Vis, 1984). In addition, mean annual soil erodibility is climate-dependent, causing seasonal variations of mean monthly soil erodibility. Furthermore, soil from temperate regions (e.g., USA and Italy) and tropical regions (e.g., Indonesia) display different erodibility performance throughout the year because of air temperature (Sanchis et al., 2008).

In summary, soil erodibility is not a straightforward concept, since it is dependent on several elements (Fig. 6) such as soil structure, soil carbon dynamics, climaterainfall erosivity, soil properties (e.g., clay-mineralogy, oxides etc.), and bio-agents (e.g, roots and microorganisms) (Bronick and Lal, 2005). Thus, soil erodibility is not a single measurable parameter because it includes all the soil characteristics (Sanchis et al., 2008). Therefore, soil erodibility should be defined in connection with specific erosion processes and erosive forces (Bryan, 2000; Wang et al., 2013). However, many interrill studies carried out as laboratory experiments play a major role in determining the relationship between intrinsic soil properties and erosional forces measured in disturbed samples (Moldenhauer and Long, 1964; Bradford et al., 1987; Truman and Bradford, 1995; Agassi and Bradford, 1999; Bradford and Foster, 1996; Bryan, 2000; Zhang et al., 2014). 

most of the contextual soil erodibility controlling factors that affect soil interrill erosion

been obliterated from the soil (i.e., the soil sample consists of disturbed soil). Therefore,

all the assessed parameters were misrepresented for the disturbed soil. In contrast, the

undisturbed soil seems to have preserved the soil field conditions, especially the soil

architecture and root network. In the undisturbed samples the soil structure with high of the hydrology connectivity between the soil surface and the soil profile. As a result a major effect on soil erodibility and soil hydrological response occurs.

\section{Acknowledgment}

We thank Verediana Fernanda Cherobim from; National Soil Erosion Research Laboratory, USDA-West Lafayette, Indiana-US and Universidade Federal do Paraná, Brazil, for useful discussion about collecting undisturbed soil samples, and Drs. Chi Hua Huang and Dennis Flanagan for provide ELT a brief, but fruitful period at the National Soil Erosion Research Laboratory, USDA. We also thank João Anésio Bednarz, Paulo Ângelo Fachin and Tatiane Wouk for their support on the laboratory experiment.

\section{References}

Agassi, M., Bradford, J.M., 1999. Methodologies for interrill soil erosion studies. Soil and Tillage Research, 49(4), 277-287.

Amézketa, E., 1999. Soil Aggregate Stability: A Review. Journal of Sustainable Agriculture, 14(2-3), 83-151.

Baets, S.D., Poesen, J., Knapen, A., Galindo, P., 2007. Impact of root architecture on the erosion-reducing potential of roots during concentrated flow. Earth Surface Processes and Landforms, 32(9), 1323-1345.

Bennett, S.J., Ashmore, P., Neuman, C.M., 2015. Transformative geomorphic research using laboratory experimentation. Geomorphology, 244, 1-8.

Bertolino, A.V.F.A., Fernandes, N.F., Miranda, J.P.L., Souza, A.P., Lopes, M.R.S., Palmieri, F., 2010. Effects of plough pan development on surface hydrology and 
on soil physical properties in Southeastern Brazilian plateau. Journal of Hydrology, 393(1-2), 94-104.

Boix-Fayos, C., Martínez-Mena, M., Arnau-Rosalén, E., Calvo-Cases, A., Castillo, V., Albaladejo, J., 2006. Measuring soil erosion by field plots: Understanding the sources of variation. Earth-Science Reviews, 78(3-4), 267-285.

Bouyoucos, G.J., 1935. The Clay Ratio as a Criterion of Susceptibility of Soils to Erosion1. Agronomy Journal, 27(9).

Bradford, J., Ferris, J., Remley, P., 1987. Interrill soil erosion processes: I. Effect of surface sealing on infiltration, runoff, and soil splash detachment. Soil Science Society of America Journal, 51(6), 1566-1571.

Bradford, J.M., Foster, G.R., 1996. Interrill Soil Erosion and Slope Steepness Factors. Soil Science Society of America Journal, 60(3), 909-915.

Bronick, C.J., Lal, R., 2005. Soil structure and management: a review. Geoderma, 124(1-2), 3-22.

Bryan, 2000. Soil erodibility and processes of water erosion on hillslope. Geomorphology, 32(3-4), 385-415.

Bryan, R.B., 1968. The development, use and efficiency of indices of soil erodibility. Geoderma, 2(1), 5-26.

Bryan, R.B., 1979. The influence of slope angle on soil entrainment by sheetwash and rainsplash. Earth Surface Processes, 4(1), 43-58.

Bryan, R., De Ploey, J., 1983. Comparability of soil-erosion measurements with different laboratory rainfall simulators. Catena Supplement, 4, 33-56.

De Baets, S., Poesen, J., Gyssels, G., Knapen, A., 2006. Effects of grass roots on the erodibility of topsoils during concentrated flow. Geomorphology, 76(1-2), 5467.

Díaz-Zorita, M., Perfect, E., Grove, J.H., 2002. Disruptive methods for assessing soil structure. Soil and Tillage Research, 64(1-2), 3-22.

Douglas, I., 1999. Hydrological investigations of forest disturbance and land cover impacts in South-East Asia: a review. Philosophical Transactions of the Royal Society of London. Series B: Biological Sciences 354, 1725-1738.

Editorial 2010. Investing in soils. Nature Geosci, 3(5), 295-295.

Ellison, W., 1950. Soil erosion by rainstorms. Science, 111(2880), 245-249.

Emmett, W.W., 1970. The hydraulics of overland flow on hillslopes. 2330-7102, US Govt. Print. Off.

Fattet, M., Fu, Y., Ghestem, M., Ma, W., Foulonneau, M., Nespoulous, J., Le Bissonnais, Y., Stokes, A., 2011. Effects of vegetation type on soil resistance to erosion: Relationship between aggregate stability and shear strength. Catena, 87(1), 60-69.

Fox, D.M., Bryan, R.B., 2000. The relationship of soil loss by interrill erosion to slope gradient. Catena, 38(3), 211-222.

Govers, G., 1992. Relationship between discharge, velocity and flow area for rills eroding loose, non-layered materials. Earth Surface Processes and Landforms, 17(5), 515-528.

Govers, G., Giménez, R., Van Oost, K., 2007. Rill erosion: Exploring the relationship between experiments, modelling and field observations. Earth-Science Reviews, 84(3-4), 87-102.

Grismer, M., 2012. Standards vary in studies using rainfall simulators to evaluate erosion. California Agriculture, 66(3), 102-107. 
Gyssels, G., Poesen, J., 2003. The importance of plant root characteristics in controlling concentrated flow erosion rates. Earth Surface Processes and Landforms, 28(4), 371-384.

Hamza, M.A., Anderson, W.K., 2005. Soil compaction in cropping systems. Soil and Tillage Research, 82(2), 121-145.

Imeson, A.C., Vis, M., 1984. Seasonal variations in soil erodibility under different landuse types in Luxembourg. Journal of soil science, 35(2), 323-331.

Kemper, W.D. and Rosenau, R.C., 1986. Aggregate stability and size distribution. In: A. Klute (Editor), Methods of Soil Analysis. Part 1. American Society of Agronomy, Soil Science Society of America, Madison,WI, 2nd., pp. 425-442.

Knapen, A., Poesen, J., Govers, G., Gyssels, G., Nachtergaele, J., 2007. Resistance of soils to concentrated flow erosion: A review. Earth-Science Reviews, 80(1-2), 75-109.

Le Bissonnais, Y., 1996. Aggregate stability and assessment of soil crustability and erodibility: I. Theory and methodology. European Journal of Soil Science, 47(4), 425-437.

Lin, H., Brooks, E., McDaniel, P., Boll, J., 2006. Hydropedology and Surface/Subsurface Runoff Processes, Encyclopedia of Hydrological Sciences. John Wiley \& Sons, Ltd.

Luk, S.-h., Abrahams, A.D., Parsons, A.J., 1986. Methodology: a simple rainfall simulator and trickle system for hydro-geomorphological experiments. Physical Geography, 7(4), 344-356.

McGarigal, K., Cushman, S., S. Stafford 2000. Multivariate Statistics for Wildlife and Ecology Research. Springer. New York.

Moldenhauer, W., Long, D.C., 1964. Influence of rainfall energy on soil loss and infiltration rates: I. Effect over a range of texture. Soil Science Society of America Journal, 28(6), 813-817.

Montgomery, D.R., 2007. Soil erosion and agricultural sustainability. Proc Natl Acad Sci U S A, 104(33), 13268-13272.

Morgan, R., 2005. Soil erosion and conservation . National Soil Resources Institute. Cranfield University. Blackwell Publishing, UK.

Mutchler, C., Murphree, C., McGregor, K., 1994. Laboratory and field plots for erosion research. Lal, R. Soil erosion research methods. Columbus, 2, 11-38.

Norvig, P., Relman, D.A., Goldstein, D.B., Kammen, D.M., Weinberger, D.R., Aiello, L.C., 2010. 2020 Visions. Nature, 463(7), 26-32.

Sanchis, M.P.S., Torri, D., Borselli, L., Poesen, J., 2008. Climate effects on soil erodibility. Earth Surface Processes and Landforms, 33(7), 1082-1097.

Shi, Z.-H., Yan, F.-L., Li, L., Li, Z.-X., Cai, C.-F., 2010. Interrill erosion from disturbed and undisturbed samples in relation to topsoil aggregate stability in red soils from subtropical China. Catena, 81(3), 240-248.

Thomaz, E.L., 2013. Rill erosion on an oxisol influenced by a thin compacted layer. Revista Brasileira de Ciência do Solo, 37, 1383-1392.

Thomaz, E.L., 2013. Slash-and-burn agriculture: Establishing scenarios of runoff and soil loss for a five-year cycle. Agriculture, Ecosystems \& Environment 168, 1-6.

Tisdall, J., Oades, J.M., 1982. Organic matter and water-stable aggregates in soils. Journal of soil science, 33(2), 141-163.

Truman, C.C., Bradford, J.M., 1995. Laboratory Determination of Interrill Soil Erodibility. Soil Science Society of America Journal, 59(2), 519-526.

USDA, N., 1998. Keys to soil taxonomy. USDA, Washington DC. 
502 Wang, B., Zheng, F., Römkens, M.J.M., Darboux, F., 2013. Soil erodibility for water erosion: A perspective and Chinese experiences. Geomorphology, 187, 1-10.

Zang, F.-B., Wang, Z.-L., Yang, M.-Y., 2014 Validating and Improving Interrill Erosion Equations. PLoS ONE, 9(2), e88275.

506

Zhang, G.-h., Liu, B.-y., Liu, G.-b., He, X.-w., Nearing, M.A., 2003. Detachment of Undisturbed Soil by Shallow Flow. Soil Science Society of America Journal, 
533 Figure captions

534 Fig. 1. Central splash pan test area surrounded by a shield collector to measure splash 535 detachment.

536 Fig. 2. Comparison of the hydro-erosional and bio-physical parameters collected from 537 undisturbed and disturbed soil.

538 Fig. 3. Overview of soil surface after rainfall simulation, and root characteristics: a)

539 undisturbed soil; b) disturbed soil; c) primary roots; d) secondary roots.

540 Fig. 4. Comparison of hydro-erosional performance of undisturbed and disturbed soil: a)

541 wash sediment, b) runoff, and c) soil moisture.

542 Fig. 5. Cluster analyses considering several hydro-erosional parameters measured for 543 undisturbed (UND) and disturbed soil (DIS).

544 Fig. 6. Diagram of contextual soil erodibility controlling factors.

545

546 
Table 1. Soil A horizon characteristics.

Soil characteristics $(0-10 \mathrm{~cm})$

Sand $(\%)$

Silt $(\%)$

Clay $(\%)$

Bulk density $(0-5 \mathrm{~cm})\left(\mathrm{g} \mathrm{cm}^{-3}\right)$

Topsoil shear strength (Kpa)

Mean particle diameter $(\mathrm{mm})$

Soil organic matter (Walkley-Black) $\left(\mathrm{g} \mathrm{dm}^{-3}\right)$

$\mathrm{pH}\left(\mathrm{CaCl}_{2} 0.01 \mathrm{M}\right)$

P (Mehlich) ( $\left.\mathrm{mg} \mathrm{dm}^{-3}\right)$

Base saturation $(\%)$

Cation Exchange Capacity $\left(\mathrm{cmol} \mathrm{dm}^{-3}\right)$
16.0

28.0

56.0

$0.85 \pm 0.05$

$33.2 \pm 5.9$

$2.96 \pm 0.18$

42.9

4.3

1.6

36.3

13.45 
Table 2. Sample characteristics soil weight and estimated soil bulk density

\begin{tabular}{ccccc} 
Splash Pan & ${ }^{1}$ Undisturbed & ${ }^{2}$ Disturbed & Undisturbed & Disturbed \\
& soil sample & soil sample & soil bulk & soil bulk \\
& weight & weight & density & density \\
& $(\mathrm{kg})$ & $(\mathrm{kg})$ & $\left(\mathrm{g} \mathrm{cm}^{-3}\right)$ & $\left(\mathrm{g} \mathrm{cm}^{-3}\right)$ \\
\hline 1 & 15.25 & 12.82 & 1.00 & 0.88 \\
2 & 15.65 & 13.37 & 1.03 & 0.91 \\
3 & 13.69 & 13.26 & 0.90 & 0.91 \\
4 & 13.54 & 13.60 & 0.89 & 0.93 \\
5 & 14.64 & 13.70 & 0.96 & 0.94 \\
6 & 15.70 & 14.22 & 1.03 & 0.97 \\
\hline 7 & 15.94 & 13.61 & 1.05 & 0.93 \\
\hline Sample soil moisture $\left(0.111 \pm 0.017 \mathrm{~m}^{3} \mathrm{~m}^{-3}\right.$, & $n=7)$. & & 0.93 \\
\hline Standard deviation & 1.06 & & & \\
\hline
\end{tabular}


Table 3. Summary of hydro-erosional variable changes compared for undisturbed and disturbed soil

Parameter

Ratio

Undisturbed/Disturbed

Wash sediment $\left(\mathrm{kg} \mathrm{m}^{-2} \mathrm{~h}^{-1}\right)$

$-9.0$

Infiltration $\left(\mathrm{mm} \mathrm{h}^{-1}\right)$

$+4.7$

Final runoff coefficient $(\%)$

Runoff $\left(\mathrm{mm} \mathrm{h}^{-1}\right)$

$-2.8$

Topsoil shear strength $(\mathrm{kPa})$

$+2.4$

Splash $\left(\mathrm{kg} \mathrm{m}^{-2} \mathrm{~h}^{-1}\right)$

Sediment yield $\left(\mathrm{kg} \mathrm{m}^{-2} \mathrm{~h}^{-1}\right)$

$-2.0$

Mean particle size (mm)

$+1.4$

Soil moisture $\left(\mathrm{m}^{3} \mathrm{~m}^{-3}\right)$

$+1.3$ 
Figure 2 (Greyscale)
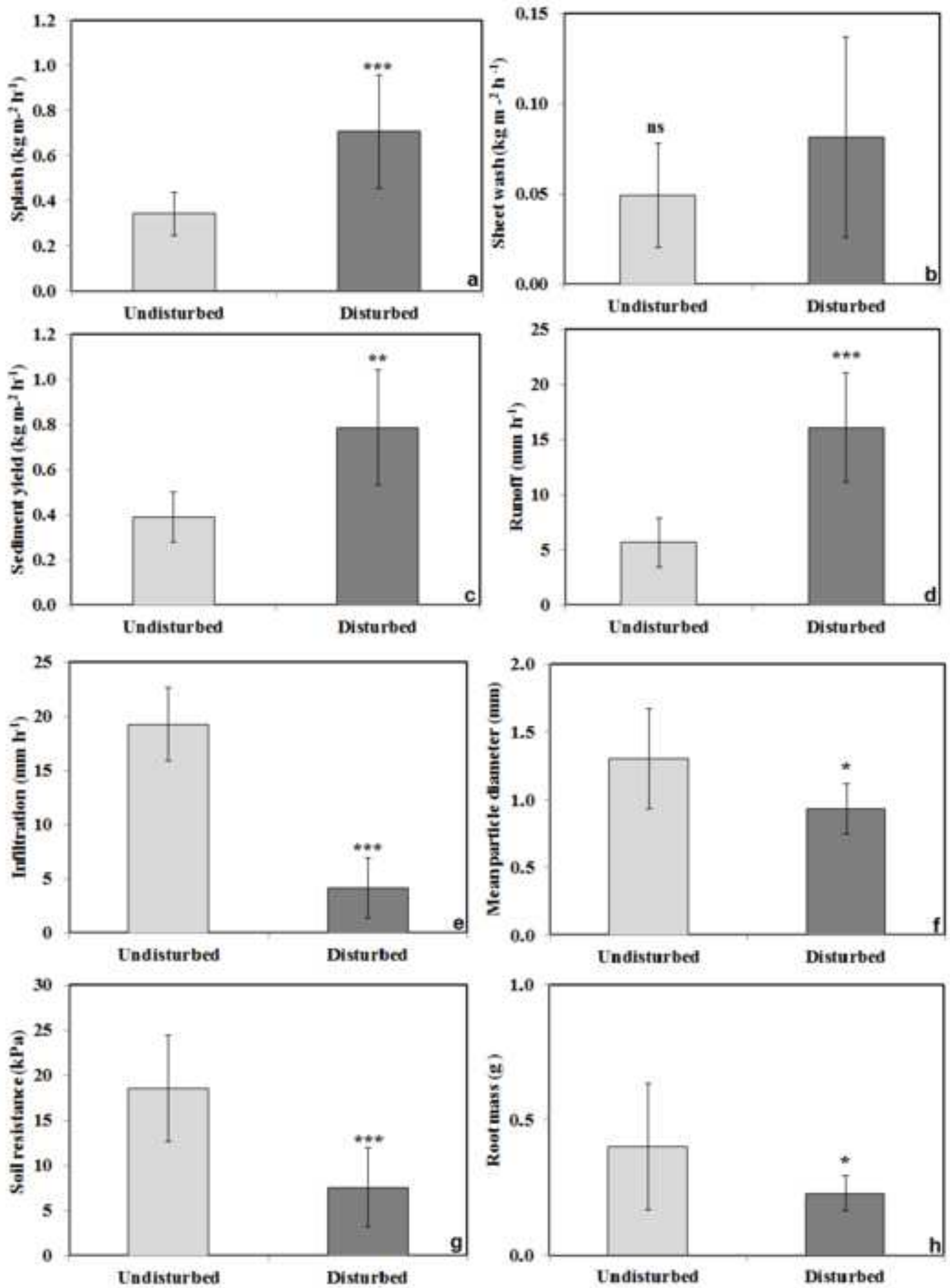


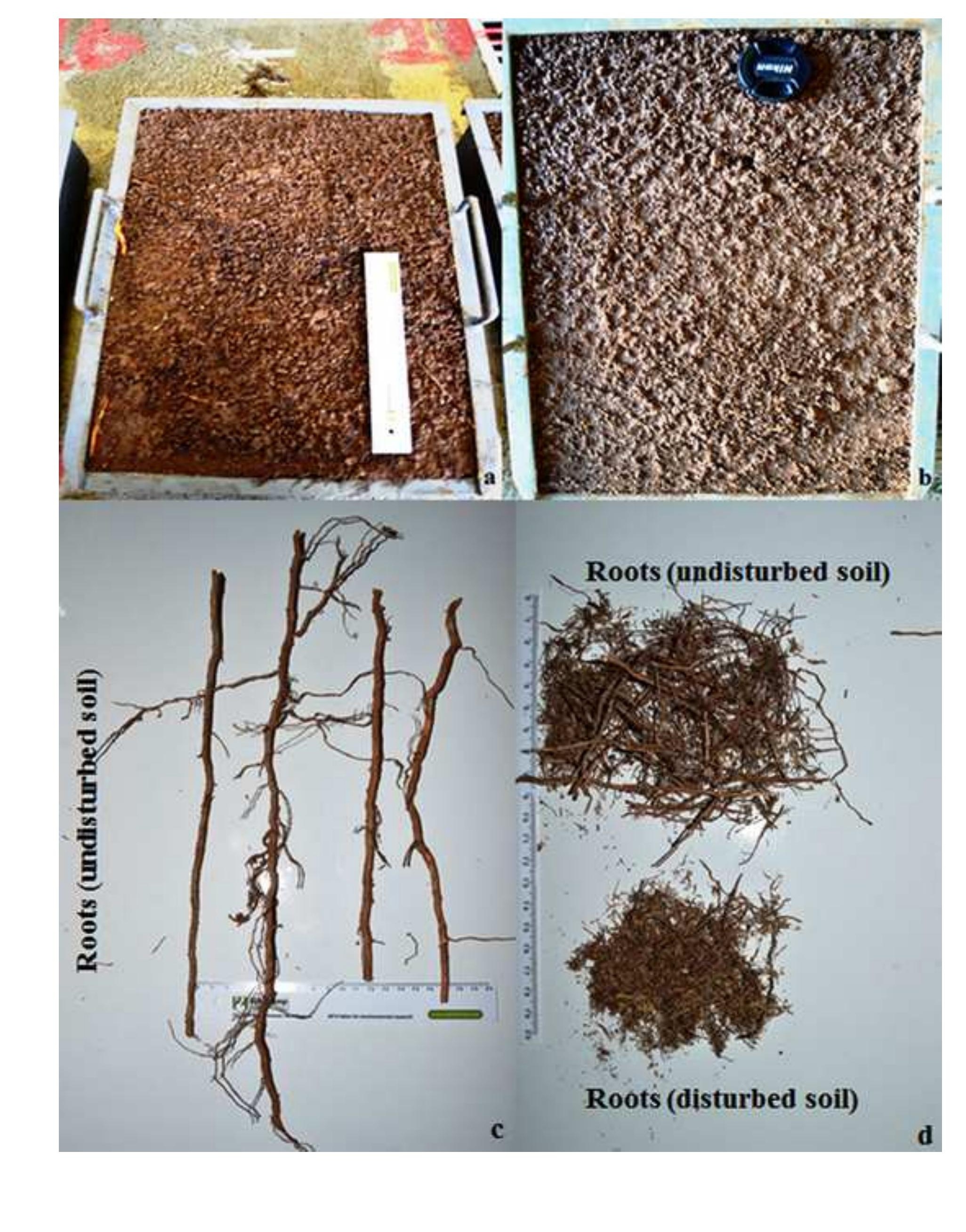

Figure 3 (Greyscale)
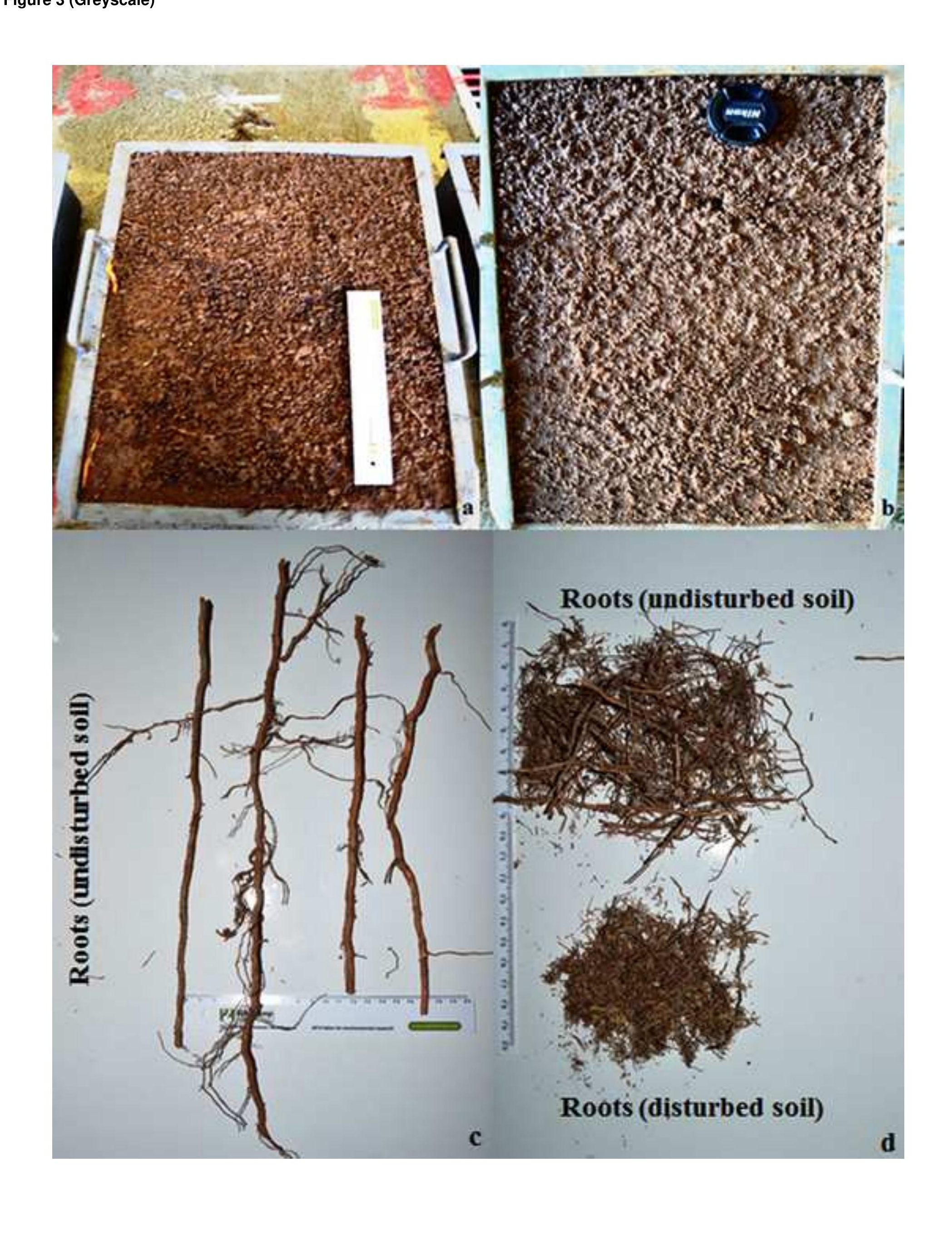
Figure 4 (Greyscale)
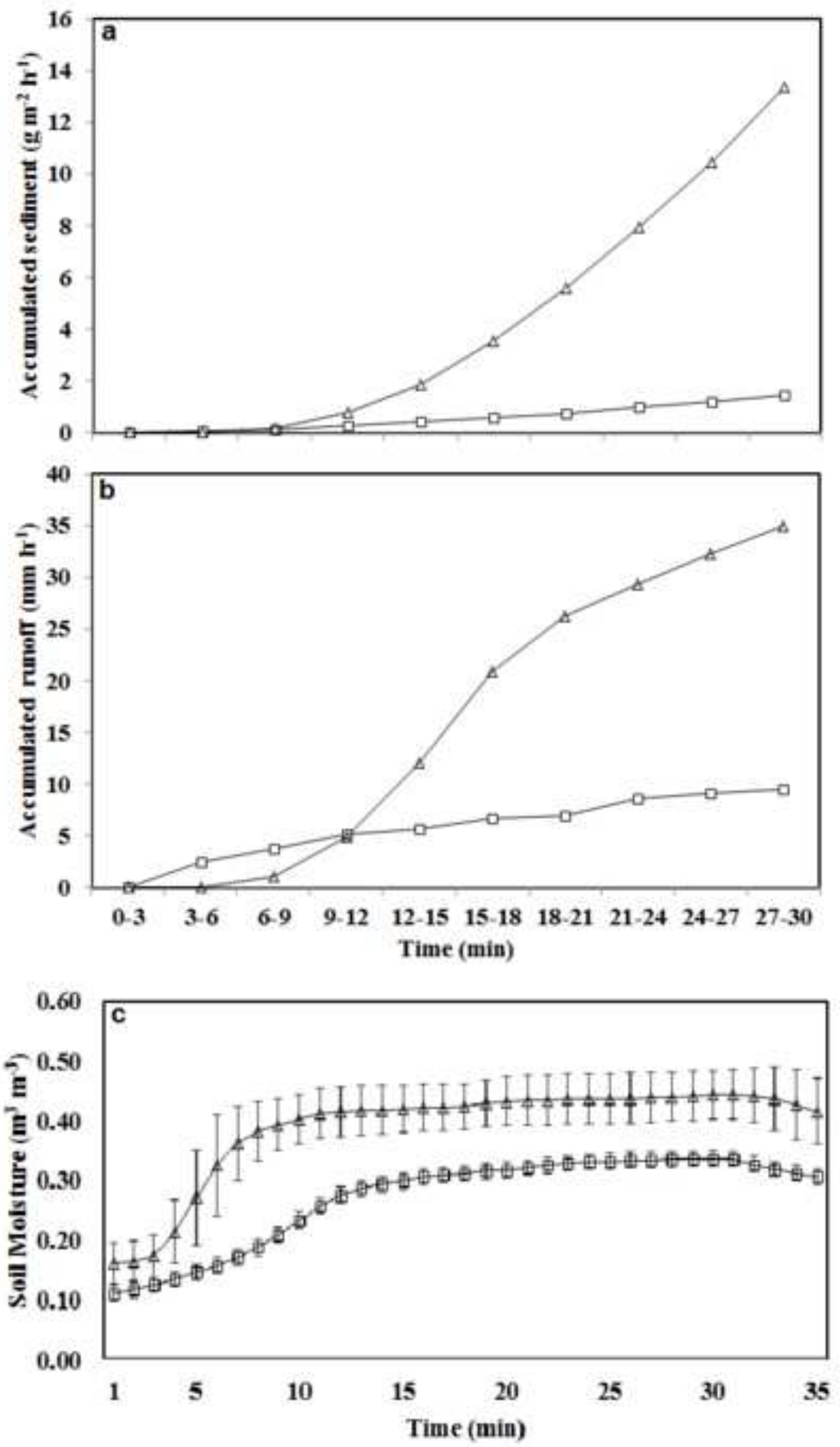

$\rightarrow$ - Indisturbed soil $\quad$-Disturbed soil 
Distance

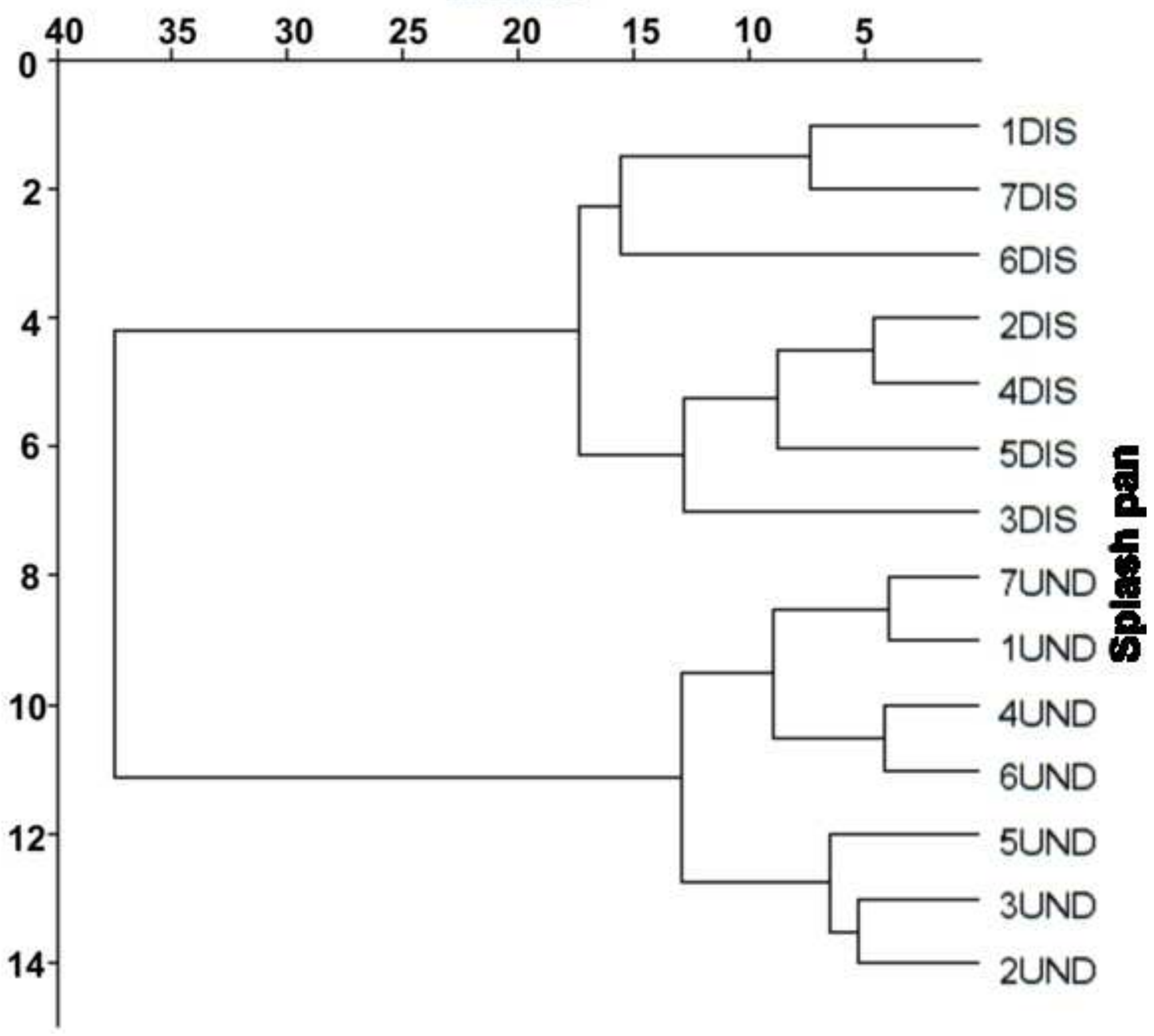




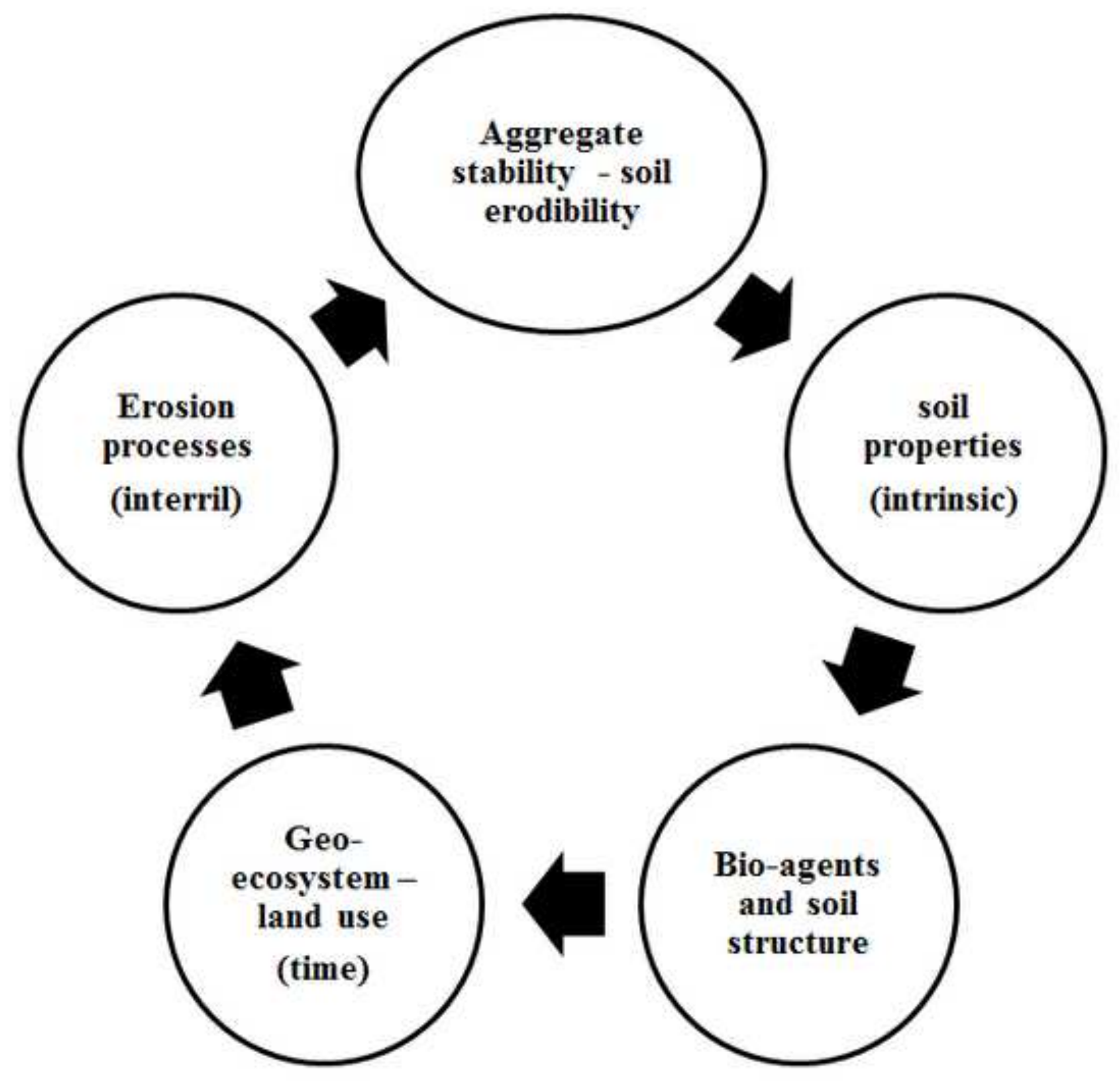

